\title{
Heterologous production of caffeic acid from tyrosine in Escherichia coli
}

\author{
J.L. Rodrigues ${ }^{\mathrm{a}, \mathrm{c}, \mathrm{d}}$, R.G. Araújo ${ }^{\mathrm{a}}$, K.L.J. Prather ${ }^{\mathrm{b}, \mathrm{c}, \mathrm{d}}$, L.D. Kluskens ${ }^{\mathrm{a}}$, L.R. Rodrigues ${ }^{\mathrm{a}, \mathrm{c}, \mathrm{d}, *}$ \\ a Centre of Biological Engineering, University of Minho, 4710-057 Braga, Portugal \\ ${ }^{\mathrm{b}}$ Department of Chemical Engineering, Synthetic Biology Engineering Research Center (SynBERC), Massachusetts Institute of Technology, Cambridge, MA \\ 02139, USA \\ ${ }^{\mathrm{c}}$ MIT-Portugal Program, Cambridge, MA, USA \\ ${ }^{\mathrm{d}}$ MIT-Portugal Program, Lisbon, Portugal
}

\section{A R T I C L E I N F O}

\section{Article history:}

Received 16 October 2014

Received in revised form

30 December 2014

Accepted 6 January 2015

Available online 14 January 2015

\section{Keywords:}

Tyrosine

p-Coumaric acid

Caffeic acid

E. coli

Biosynthesis

Synthetic biology

\begin{abstract}
A B S T R A C T
Caffeic acid is a plant secondary metabolite and its biological synthesis has attracted increased attention due to its beneficial effects on human health. In this study, Escherichia coli was engineered for the production of caffeic acid using tyrosine as the initial precursor of the pathway. The pathway design included tyrosine ammonia lyase (TAL) from Rhodotorula glutinis to convert tyrosine to $p$-coumaric acid and 4coumarate 3-hydroxylase (C3H) from Saccharothrix espanaensis or cytochrome P450 CYP199A2 from Rhodopseudomonas palustris to convert $p$-coumaric acid to caffeic acid. The genes were codon-optimized and different combinations of plasmids were used to improve the titer of caffeic acid. TAL was able to efficiently convert $3 \mathrm{mM}$ of tyrosine to $p$-coumaric acid with the highest production obtained being $2.62 \mathrm{mM}$ (472 mg/L). CYP199A2 exhibited higher catalytic activity towards p-coumaric acid than C3H. The highest caffeic acid production obtained using TAL and CYP199A2 and TAL and C3H was $1.56 \mathrm{mM}(280 \mathrm{mg} / \mathrm{L})$ and $1 \mathrm{mM}(180 \mathrm{mg} / \mathrm{L})$, respectively. This is the first study that shows caffeic acid production using CYP199A2 and tyrosine as the initial precursor. This study suggests the possibility of further producing more complex plant secondary metabolites like flavonoids and curcuminoids.
\end{abstract}

(c) 2015 Elsevier Inc. All rights reserved.

\section{Introduction}

Caffeic acid is a natural phenolic compound derived from the phenylpropanoid pathway in plants. Phenylpropanoic acids, especially caffeic acid, have attracted an increased attention owing to their valuable properties, including antioxidant [1], antiinflammatory [2], anticancer [3], antiviral [4], antidiabetic [5] and antidepressive [6]. Due to its pharmaceutical applications there is an established market for caffeic acid production. Caffeic acid is mainly obtained by extraction from plants and these extraction

Abbreviations: TAL, tyrosine ammonia lyase; $\mathrm{C} 3 \mathrm{H}, 4$-coumarate 3-hydroxylase; $\mathrm{PAL}$, phenylalanine ammonia lyase; $\mathrm{C} 4 \mathrm{H}$, cinnamate-4-hydroxylase; $4 \mathrm{HPA} 3 \mathrm{H}$, hydroxyphenylacetate 3-hydroxylase; 4CL, 4-coumarate-CoA ligase; MCSs, multiple cloning sites; PCR, polymerase chain reaction; RBS, ribosome binding site; HPLC, high-performance liquid chromatography; SDS-PAGE, sodium dodecyl sulfate-polyacrylamide gel electrophoretic.

* Corresponding author at: Centre of Biological Engineering, University of Minho, 4710-057 Braga, Portugal. Tel.: +351 253604 401; fax: +351 253604429 .

E-mail addresses: joana.joanalucia@deb.uminho.pt (J.L. Rodrigues), rafa.gomes.ar@gmail.com (R.G. Araújo), kljp@mit.edu (K.L.J. Prather), kluskens@deb.uminho.pt (L.D. Kluskens), lrmr@deb.uminho.pt (L.R. Rodrigues). methods include high temperatures, treatment with petroleum and solvent extraction (methanol, ethyl acetate), thus being energyintensive and environmentally unfriendly [7]. Moreover, the yields obtained are low because it accumulates at low levels in plant cells. To meet the phenylpropanoids market needs, it is imperative to look for new green and environmental production methods to replace the traditional extraction one. One way to achieve high levels of caffeic acid is the production via engineered microorganisms, such as Escherichia coli [8-10].

Natural caffeic acid production starts with the deamination of the amino acid phenylalanine which is converted to cinnamic acid by phenylalanine ammonia lyase (PAL) (Fig. 1). Then, cinnamic acid is converted to $p$-coumaric acid by cinnamate-4-hydroxylase $(\mathrm{C} 4 \mathrm{H})$, and caffeic acid is obtained from $p$-coumaric acid using 4coumarate 3-hydroxylase $(\mathrm{C} 3 \mathrm{H})$. Tyrosine can also be used as a precursor as some PALs also have tyrosine ammonia lyase (TAL) activity [11,12]. Since tyrosine already possesses a 4-hydroxyl group, its use is advantageous as it can be directly converted to p-coumaric acid, thus decreasing the number of steps to produce caffeic acid. Also, using TAL, the $\mathrm{C} 4 \mathrm{H}$ enzyme that is essential for caffeic acid production in plants and has not yet been successfully expressed in prokaryotic organisms [13] is not needed anymore. 


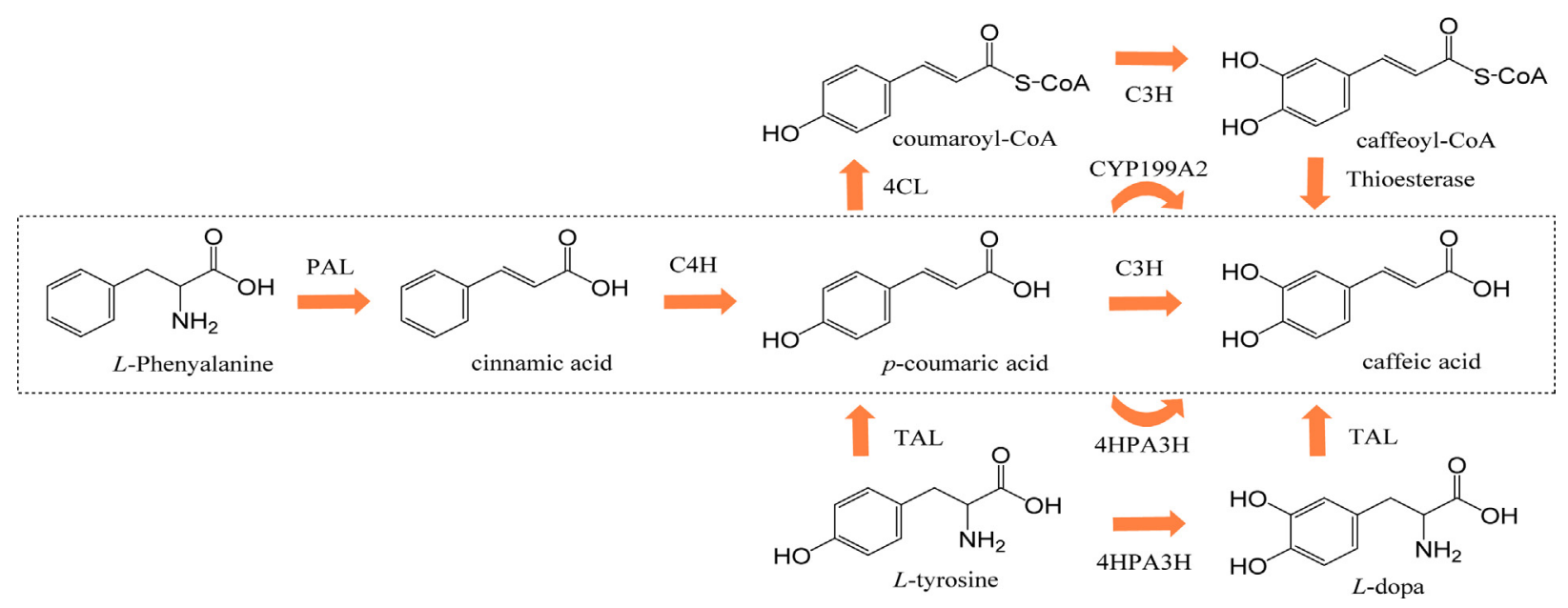

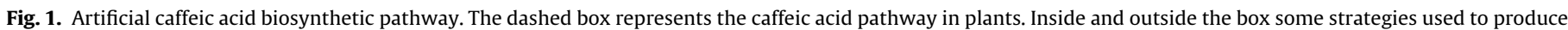

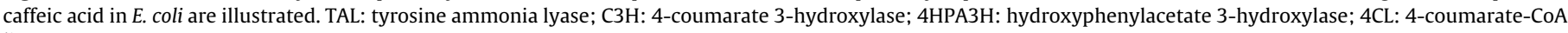
ligase.

In the last decade several efforts have been conducted to produce caffeic acid using microorganisms. Berner et al. [14] identified sam8 and sam5 genes, encoding TAL and $\mathrm{C} 3 \mathrm{H}$ involved in caffeic acid biosynthesis in the actinomycete Saccharothrix espanaensis and expressed them in Streptomyces fradiae XKS. After that, these enzymes were used to produce caffeic acid in E. coli (Table 1). Other bacterial TAL (Rhodobacter capsulatus and Rhodotorula glutinis) were also used for the production of $p$-coumaric acid and hydroxyphenylacetate 3-hydroxylase (4HPA3H) from E. coli or Pseudomonas aeruginosa, and cytochrome P450 CYP199A2 from

Table 1

Caffeic acid production in Escherichia coli. Genes/organisms used in the caffeic acid biosynthetic pathway, fermentation conditions and yields.

\begin{tabular}{|c|c|c|c|}
\hline Genes - organisms ${ }^{\mathrm{a}}$ & Fermentation conditions & Titer $(\mathrm{mg} / \mathrm{L})^{\mathrm{b}}$ & Reference \\
\hline $\begin{array}{l}\mathrm{TAL}-\mathrm{S} . \text { espanaensis } \\
\mathrm{C} 3 \mathrm{H}-\mathrm{S} . \text { espanaensis }\end{array}$ & $\begin{array}{l}\text { First induction in LB at } 37^{\circ} \mathrm{C} \text {. After } 5 \mathrm{~h} \\
\text { cells were transferred to M9 medium } \\
\text { (glucose) at } 26^{\circ} \mathrm{C} \text { for } 36 \mathrm{~h}\end{array}$ & (not mentioned) & Choi et al. [15] \\
\hline $\begin{array}{l}\text { TAL }-R . \text { capsulatus } \\
\text { 4HPA3H - E. coli } \\
\Delta \text { tyrR; tyrA }{ }^{\mathrm{fbr}}-p p s A-t k t A-\text { aroG }^{\mathrm{fbr}}\end{array}$ & $\begin{array}{l}\text { M9 medium (glucose and glycerol) at } \\
37^{\circ} \mathrm{C} \text {. After induction shake flasks were } \\
\text { transferred to } 30^{\circ} \mathrm{C} \text { for } 48 \mathrm{~h}\end{array}$ & $\begin{array}{l}50.2 \text { (TYR strain) } \\
12.1 \text { (wild-type) }\end{array}$ & Lin and Yan [16] \\
\hline $\begin{array}{l}\text { TAL and opTAL - S. espanaensis } \\
\text { C3H - S. espanaensis } \\
\Delta \text { tyrR; tyrA } A^{\mathrm{fbr}}-\text { aro }^{\mathrm{fbr}}\end{array}$ & $\begin{array}{l}\text { First induction in LB at } 37^{\circ} \mathrm{C} \text {. After } 5 \mathrm{~h} \\
\text { cells were harvested and transferred to } \\
\text { M9 medium (glucose) at } 26^{\circ} \mathrm{C} \text { for } 36 \mathrm{~h} \\
\text { in shake flasks }\end{array}$ & $\begin{array}{l}150 \text { (TAL, TYR strain) } \\
40 \text { (opTAL, TYR strain) } \\
42 \text { (TAL, wild-type) } \\
14 \text { (opTAL, wild-type) }\end{array}$ & Kang et al. [17] \\
\hline $\begin{array}{l}\text { CYP199A2 (wild-type and mutant } \\
\text { F185L) - R. palustris } \\
\text { Pdr - Pseudomonas putida } \\
\text { Pux - R. palustris }\end{array}$ & $\begin{array}{l}\text { Potassium phosphate buffer (glucose } \\
\text { or glycerol) at } 30^{\circ} \mathrm{C} \text { in shake flasks for } \\
24 \mathrm{~h} .20 \mathrm{mM} \text { p-coumaric acid was } \\
\text { added }\end{array}$ & $\begin{array}{l}510 \text { (wild-type) } \\
2,800 \text { (mutant) }\end{array}$ & Furuya et al. [8] \\
\hline $\begin{array}{l}\mathrm{TAL}-R \text {. glutinis } \\
\mathrm{C} 3 \mathrm{H}-\mathrm{S} \text {. espanaensis } \\
\Delta \text { pheA } \Delta \text { tyrR; } \text { tyrA }^{\mathrm{fbr}}-\operatorname{aroG}^{\mathrm{fbr}}\end{array}$ & $\begin{array}{l}\text { MOPS medium (glucose or xylose), } \\
\text { synthetic medium (glucose or xylose) } \\
\text { or LB (glucose or xylose) at } 37^{\circ} \mathrm{C} \text { for } \\
72 \mathrm{~h} \text { in test tubes; synthetic medium } \\
\text { (glucose) at } 37^{\circ} \mathrm{C} \text { for } 7 \text { days in } \\
\text { bioreactor }\end{array}$ & $\begin{array}{l}88 \text { (LB, glucose, test tube) } \\
106 \text { (bioreactor) }\end{array}$ & Zhang and Stephanopoulos $[18]^{c}$ \\
\hline $\begin{array}{l}\text { TAL }- \text { R. glutinis } \\
\text { 4HPA3H - E. coli } \\
\Delta \text { pheA; tyrA } A^{\mathrm{fbr}}-\text { ppsA-tktA-aroG } G^{\mathrm{fbr}}\end{array}$ & $\begin{array}{l}\text { M9 medium (yeast extract and } \\
\text { glycerol, or glucose and glycerol) at } \\
37^{\circ} \mathrm{C} \text { for } 72 \mathrm{~h} \text { in shake flasks. } 20 \mathrm{mM} \\
\text {-coumaric acid fed } 3 \mathrm{~h} \text { after induction } \\
\text { and } 3 \mathrm{mM} \text { added afterward (wild-type } \\
\text { case) }\end{array}$ & $\begin{array}{l}\text { 3,820 (wild-type) } \\
766.68 \text { (TYR strain) }\end{array}$ & Huang et al. [10] \\
\hline 4HPA3H - P. aeruginosa & $\begin{array}{l}\text { Potassium phosphate buffer (glucose } \\
\text { or glycerol) at } 30^{\circ} \mathrm{C} \text { for } 24 \mathrm{~h} \text { in shake } \\
\text { flasks. } 20 \mathrm{mM} \text { of } p \text {-coumaric acid was } \\
\text { added } 4 \text { times }\end{array}$ & 10,200 & Furuya and Kino [9] \\
\hline
\end{tabular}

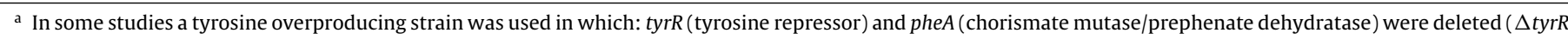

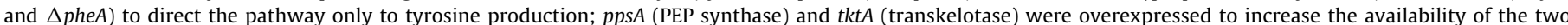

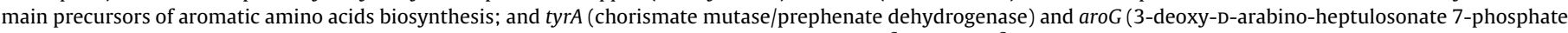

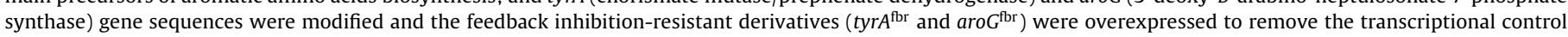
mediated by tyrosine and phenylalanine. opTAL means codon-optimized TAL.

b TYR strain - tyrosine overproducing strain.

c An alternative route through coumaroyl-CoA and caffeoyl-CoA (Fig. 1) using 4CL from $P$. crispus and E. coli endogenous thiosterase was tested to increase the yield but it was not successful. 
Rhodopseudomonas palustris was proved to convert $p$-coumaric acid to caffeic acid with a high yield.

In this study, we describe the production of caffeic acid from tyrosine or $p$-coumaric acid. To convert tyrosine to $p$-coumaric acid we used TAL from $R$. glutinis. $p$-Coumaric acid was converted to caffeic acid using C3H from S. espanaensis or CYP199A2 from $R$. palustris. Although all these genes have previously been used in the caffeic acid production, it is important to mention that, as far as we know, the caffeic acid production from tyrosine using CYP199A2 in the pathway has never been attempted. Additionally, in the current study, the titers of caffeic acid obtained using TAL and $\mathrm{C} 3 \mathrm{H}$ genes were higher than the ones reported in other studies using the same genes. These high yields were obtained by using different combinations of plasmids and genetic arrangements.

Furthermore, it is important to mention that the caffeic acid pathway can be further used to produce other products of the phenylpropanoid pathway with high added-value like flavonoids and curcuminoids.

\section{Materials and methods}

\subsection{Bacterial strains, plasmids and chemicals}

E. coli ElectroMAX ${ }^{\mathrm{TM}}$ DH10B competent cells (Invitrogen/Life Technologies, Carlsbad, CA, USA) were used for molecular cloning and vector propagation. E. coli K-12 MG1655(DE3) [19] was used as the host for the expression of genes under the control of the T7 promoter.

Pseudomonas putida JCM 6157 strain (ATCC 17453, Manassas, VA, USA) and $R$. palustris CGA009 gDNA (ATCC BAA-98) were used to amplify the $p d r$ and pux genes. The characteristics of all the strains and plasmids used in this study are described in Table 2.

Restriction, ligation and Q5 enzymes (NEB, Ipswich, MA, USA), QIAprep Spin Miniprep Kit (Qiagen, Germantown, MD, USA), DNA Clean and Concentrator and Gel DNA Recovery Kits (Zymo Research, Orange, CA, USA) and Wizard ${ }^{\circledR}$ Genomic DNA
Purification Kit (Promega, Madison, WI, USA) were used according to the instructions provided by the manufacturers.

L-Tyrosine, p-coumaric acid and caffeic acid were purchased from Sigma-Aldrich (Steinheim, Germany), isopropyl $\beta$-D-thiogalactopyranoside (IPTG) and Luria-Bertani (LB) medium from NZYTech (Lisbon, Portugal) and anhydrotetracycline (aTc) from Acros (Geel, Belgium). Glucose (Acros), $\mathrm{Na}_{2} \mathrm{HPO}_{4}$ (Scharlau, Sentmenat, Spain), $\mathrm{MgSO}_{4}, \mathrm{KH}_{2} \mathrm{PO}_{4}$ (Riel-de Haën, Seelze, Germany), $\mathrm{NH}_{4} \mathrm{Cl}, \mathrm{NaCl}, \mathrm{CaCO}_{3}$ (Panreac, Barcelona, Spain) and thiamine (Fisher Scientific Loughborough, UK) were used to prepare the M9 modified salt medium. The following mineral traces and vitamins were supplemented to the M9 medium: $\mathrm{FeCl}_{3}$ $\mathrm{ZnCl}_{2}, \mathrm{CoCl}_{2}, \mathrm{CuCl}_{2}$, nicotinic acid (Riedel-de Haën), $\mathrm{NaMoO}_{4}, \mathrm{H}_{2} \mathrm{BO}_{3}$, pyridoxine biotin, folic acid (Merck), riboflavin and pantothenic acid (Sigma Aldrich). Ampicillin (Applichem, Darmstadt, Germany), chloramphenicol, kanamycin (NZYTech) and spectinomycin (Panreac) were used when necessary.

\subsection{Codon-optimization and synthesis of TAL, C3H and CYP199A2}

TAL, C3H and CYP199A2 genes were codon-optimized for $E$. coli, synthesized and cloned in pUC57 vector by GenScript (Piscataway, NJ, USA). In addition to codonoptimization, the phenylalanine residue at 185 position (F185) of CYP199A2 was replaced by leucine (F185L) [8]. The DNA sequences of the codon-optimized genes are provided in Table 3.

\subsection{Construction of plasmids}

The genes encoding TAL and $\mathrm{C} 3 \mathrm{H}$ were expressed in E. coli cells using the pETDuet-1, pCDFDuet-1, pRSFDuet-1 and pKVS45 vectors (Table 2). The gene encoding CYP199A2 mutant was cloned in pCDFDuet-1 and CYP199A2 redox partners, $p d r$ and pux genes, were cloned in an operon in pKVS45 using restriction enzymes. All the primers used are summarized in Table 4. TAL and CYP199A2 were also cloned in an operon using Phusion DNA polymerase (NEB) and overlap extension polymerase chain reaction (PCR) [21]. The ribosome binding site (RBS) chosen was the same used in pETDuet-1, pCDFDuet-1 and pRSFDuet-1. Reverse primers of TAL gene were overlapped with forward primers of the CYP199A2 gene to introduce the RBS and spacer. Briefly, the TAL and CYP199A2 genes were amplified and the overlapping strands of these intermediate products hybridized in a subsequent PCR and were

Table 2

Bacterial strains and plasmids used in this study.

\begin{tabular}{|c|c|c|}
\hline Strains & Relevant genotype & Source \\
\hline E. coli ElectroMAX DH10B & $\begin{array}{l}F^{-} \text {mcrA } \Delta(\text { mrr-hsdRMS-mcrBC }) \varphi 80 \text { lacZ } \Delta M 15 \Delta \text { lacX74 } \\
\text { recA1 endA1 araD139 } \Delta(\text { ara, leu }) 7697 \text { galU galK } \lambda^{-} \text {rpsL } \\
\text { nupG }\end{array}$ & Invitrogen/Life Technologies \\
\hline E. coli $\mathrm{K}-12 \mathrm{MG} 1655(\mathrm{DE} 3)$ & $F^{-} \lambda^{-} i l v G^{-} r f b^{-} 50 r p h^{-} 1 \lambda(\mathrm{DE} 3)$ & [19] \\
\hline P. putida JCM 6157 & & ATCC 17453 \\
\hline
\end{tabular}

Genomic DNA

Source

R. palustris CGA009

ATCC BAA-98D-5

Plasmids

pETDuet-1

pCDFDuet-1

pRSFDuet-1

pKVS45

pUC57_TAL

pUC57_C3H

pUC57_CYP199A2

pETDuet_TAL

pETDuet_C3H

pETDuet_TAL_C3H

pCDFDuet_TAL

pCDFDuet_C3H

pCDFDuet_CYP

pCDFDuet_CYP (+7aa)

pCDFDuet_TAL_CYP

pCDFDuet_TAL_CYP (+7aa)

pCDFDuet_TAL_CYP_op

pCDFDuet_TAL_CYP(+7aa)_op

pKVS45_TAL

pKVS45_C3H

pRSFDuet_TAL

pRSFDuet_C3H

pKVS45_Pdr_Pux_op

pETDuet_Pdr_Pux_op
Construct

ColE1(pBR322) ori, lacI, double T7lac, Amp ${ }^{\mathrm{R}}$

CloDF13 ori, lacI, double T7lac, Strep ${ }^{R}$

RSF ori, lacI, double T7lac, $\mathrm{Kan}^{\mathrm{R}}$

p15A ori, tetR, $\mathrm{P}_{\text {tet }}, \mathrm{Amp}^{\mathrm{R}}$

pUC57 carrying codon-optimized TAL from $R$. glutinis

pUC57 carrying codon-optimized C3H from S. espanaensis

pUC57 carrying codon-optimized CYP199A2 from $R$. palustris

pETDuet-1 carrying codon-optimized TAL from $R$. glutinis

pETDuet-1 carrying codon-optimized $\mathrm{C} 3 \mathrm{H}$ from S. espanaensis

pETDuet_TAL carrying codon-optimized C3H from S. espanaensis

pCDFDuet-1 carrying codon-optimized TAL from $R$. glutinis

pCDFDuet-1 carrying codon-optimized C3H from S. espanaensis

pCDFDuet-1 carrying codon-optimized CYP199A2 from $R$. palustris

pCDFDuet-1 carrying codon-optimized CYP199A2 from $R$. palustris with the first 7 amino acids

pCDFDuet_TAL carrying codon-optimized CYP199A2 from $R$. palustris

pCDFDuet TAL carrying CYP199A2 from $R$. palustris with the first 7 amino acids

pCDFDuet-1 carrying codon-optimized TAL from $R$. glutinis and CYP199A2 from $R$. palustris in an operon

pCDFDuet-1 carrying codon-optimized TAL from $R$. glutinis and CYP199A2 from $R$. palustris with the first 7

amino acids in an operon

pKVS45 carrying codon-optimized TAL from $R$. glutinis

pKVS45 carrying codon-optimized $\mathrm{C} 3 \mathrm{H}$ from $S$. espanaensis

pRSFDuet-1 carrying codon-optimized TAL from $R$. glutinis

pRSFDue-1t carrying codon-optimized $\mathrm{C} 3 \mathrm{H}$ from $\mathrm{S}$. espanaensis

pKVS45 carrying Pdr from $P$. putida and Pux from $R$. palustris in an operon

pETDuet-1 carrying Pdr from P. putida and Pux from R. palustris in an operon
Source

Novagen

Novagen

Novagen

[20]

GenScript

GenScript

GenScript

This study

This study

This study

This study

This study

This study

This study

This study

This study

This study

This study

This study

This study

This study

This study

This study This study 
Table 3

Gene sequences of TAL, C3H and CYP199A2 with codon optimization.

\begin{tabular}{|c|c|}
\hline Gene & Sequence \\
\hline $\begin{array}{l}\text { TAL (Rhodotorula } \\
\text { glutinis) }\end{array}$ & $\begin{array}{l}\text { ATGGCTCCGCGTCCGACCTCGCAATCCCAAGCTCGCACCTGCCCGACCACCCAAGTTACCCAAGTTGACATCGTTGAAAAAATGCTGGCGGCGCCGA- } \\
\text { CCGATTCGACGCTGGAACTGGACGGCTATAGCCTGAACCTGGGTGATGTGGTTTCTGCAGCACGTAAAGGTCGTCCGGTGCGTGTTAAAGATTCAGA- } \\
\text { CGAAATTCGCTCGAAAATCGATAAAAGCGTGGAATTCTGCGTAGCCAGCTGAGCATGTCTGTTTACGGCGTCACCACGGGTTTCGGCGGTTCAGC- } \\
\text { CGATACCCGCACGGAAGACGCCATTTCGCTGCAGAAAGCACTGCTGGAACATCAACTGTGCGGCGTGCTGCCGAGCTCTTTTGATAGCTTCCGCCT- } \\
\text { GGGCCGTGGTCTGGAAAACTCTCTGCCGCTGGAAGTCGTGCGTGGTGCAATGACCATCCGTGTTAATTCCCTGACGCGCGGTCATTCAGCTGTCCGTC- } \\
\text { TGGTTGTCCTGGAAGCGCTGACCAACTTTCTGAATCACGGTATTACGCCGATCGTGCCGCTGCGTGGTACCATTAGTGCATCCGGTGATCTGAGCCCGC- } \\
\text { TGTCTTATATTGCAGCTGCGATCTCTGGCCACCCGGACAGTAAAGTTCATGTGGTTCACGAGGGTAAAGAAAAAATCCTGTACGCCCGTGAAGCTATGG- } \\
\text { CGCTGTTCAACCTGGAACCGGTCGTGCTGGGCCCGAAAGAAGGCCTGGGTCTGGTGAATGGTACGGCTGTTCAGCGTCGATGGCCACCCTGGCACTGCA- } \\
\text { TGATGCCCACATGCTGAGCCTGCTGAGCCAGTCTCTGACCGCGATGACGGTCGAAGCGATGGTGGGCCATGCAGGTAGCTTTCATCCGTTCCTGCACGAT- } \\
\text { GTGACCCGTCCGCACCCGACGCAGATTGAAGTTGCAGGCAACATCCGCAAACTGCTGGAAGGTAGCCGTTTGCGGTGCATCACGAAGAAGAAGTGAAAG- } \\
\text { TGAAAGATGACGAAGGCATTCTGCGCCAGGATCGTTATCCGCTGCGTACCAGTCCGCAATGGCTGGGTCCGCTGGTCTCCGACCTGATTCATGCCCACGCA- } \\
\text { GTGCTGACCATCGAAGCGGGTCAGAGTACCACGGATAACCCGCTGATTGACGTGGAAAATAAAACCTCTCATCACGGCGGTAACTTTCAAGCCGCAGCTGT- } \\
\text { TGCCAATACGATGGAAAAAACGCGCCTGGGCCTGGCACAGATCGGTAAACTGAATTTCACCCAACTGACGGAAATGCTGAACGCAGGCATGAATCGTGGTC- } \\
\text { TGCCGAGCTGCCTGGCAGCAGAAGATCCGAGTCTGTCCTATCATTGTAAAGGCCTGGACATTGCAGCTGCGGCCTACACCTCTGAACTGGGTCATCTGGCGA- } \\
\text { ACCCGGTTACCACGCACGTCCAGCCGGCTGAAATGGCGAACCAAGCCGTGAATTCCCTGGCACTGATCTCAGCTCGTCGCACCACGGAATCGAATGATGTCC- } \\
\text { TGAGCCTGCTGCTGGCGACCCATCTGTATTGTGTTCTGCAGGCTATTGACCTGCGCGCGATCGAATTGAATTCAAAAAACAGTTTGGCCCGGCTATTGTG- } \\
\text { AGCCTGATCGATCAACACTTCGGCTCTGCCATGACCGGTAGTAACCTGCGTGACGAACTGGTGGAAAAAGTTAATAAAACGCTGGCCAAACGCCTGGAACA- } \\
\text { GACCAACAGTTACGATCTGGTGCCGCGTTGGCATGACGCATTTCCTTCGCAGCTGGTACGGTTGTCGAAGTTCTGAGTTCCACCTCACTGTCGCTGGCGG- } \\
\text { CCGTCAATGCCTGGAAAGTGGCAGCTGCGGAAAGTGCAATTCCCTGACCCGCCAAGTGCGTGAAACGTTTGGTCAGCAGCATCGACGTCATCGCCGGCA- } \\
\text { CTGAGCTATCTGTCTCCGCGCACCCAAATTCTGTACGCTTTTGTTCGTGAAGAACTGGGCGTCAAAGCGCGTCGCGGCGATGTTTCCTGGGTAAACAGGA- } \\
\text { AGTGACCATCGGTAGTAATGTTTCCAAAATCTATGAAGCTATCAAAAGCGGTCGTATCAATAATGTGCTGCTGAAAATGCTGGCATAA }\end{array}$ \\
\hline
\end{tabular}

С3H (Saccharothrix ATGACGATTACCTCTCCGGCACCGGCTGGTCGCCTGAACAATGTCCGCCCGATGACGGGTGAAGAATACCTGGAATCCCTGCGTGACGGCCGTGAAGespanaensis) TGTATATTTACGGTGAACGCGTCGATGACGTGACCACGCATCTGGCGTTCCGCAACAGCGTTCGTTCTATCGCCCGCCTGTATGATGTCCTGCACGACCCGGCATCCGAAGGTGTTCTGCGTGTCCCGACCGATACGGGTAATGGTGGTTTTACCCATCCGTTTTTCAAAACGGCGCGTAGCTCTGAAGACCTGGTGGCGGCCCGTGAAGCCATTGTCGGCTGGCAACGCCTGGTGTATGGCTGGATGGGTCGTACCCCGGATTACAAAGCAGCGTTTTTCGGTACGCTGGACGCTAACGCGGAATTTTATGGCCCGTTCGAAGCCAATGCACGTCGCTGGTATCGTGATGCACAGGAACGCGTTCTGTACTTCAACCATGCTATCGTTCACCCGCCGGTCGATCGTGACCGTCCGGCTGATCGTACCGCAGACATTTGCGTCCATGTGGAAGAAGAAACGGATTCAGGCCTGATCGTGTCGGGTGCCAAAGTGGTTGCAACCGGTTCTGCTATGACGAACGCGAATCTGATTGCCCACTATGGTCTGCCGGTTCGCGATAAAAAATTTGGCCTGGTGTTCACCGTTCCGATGAACAGTCCGGGTCTGAAACTGATCTGTCGTACCTCCTATGAACTGATGGTGGCCACGCAGGGCTCACCGTTTGATTACCCGCTGAGTTCCCGCCTGGATGAAAATGACAGCATTATGATCTTTGATCGTGTTCTGGTCCCGTGGGAAAACGTTTTCATGTACGACGCAGGCGCGGCCAATAGCTTTGCTACCGGCTCTGGTTTCCTGGAACGCTTTACCTTCCATGGTTGCACGCGTCTGGCAGTGAAACTGGATTTTATTGCAGGCTGTGTTATGAAAGCTGTGGAAGTTACCGGCACCACGCACTTCCGCGGTGTTCAGGCGCAAGTCGGCGAAGTGCTGAACTGGCGTGATGTCTTTTGGGGTCTGTCGGACGCTATGGCGAAAAGTCCGAATTCCTGGGTGGGCGGTAGCGTTCAGCCGAACCTGAATTATGGCCTGGCCTACCGCACCTTTATGGGCGTGGGTTATCCGCGTATTAAAGAAATTATCCAGCAAACGCTGGGCTCTGGTCTGATCTACCTGAACTCATCGGCAGCTGATTGGAAAAATCCGGACGTTCGCCCGTATCTGGATCGTTACCTGCGCGGCAGTCGTGGTATTCAGGCAATCGATCGTGTCAAACTGCTGAAACTGCTGTGGGACGCAGTGGGTACCGAATTCGCAGGTCGTCATGAACTGTATGAACGCAACTACGGCGGTGATCACGAAGGTATTCGTGTGCAGACCCTGCAAGCCTATCAGGCAAATGGTCAAGCGGCCGCACTGAAAGGCTTTGCGGAACAGTGTATGTCGGAATATGACCTGGATGGCTGGACCCGCCCGGACCTGATTAACCCGGGCACGTAA

CYP199A2 ATGACGACCGCTCCGAGCCTGATGCCGGTTACGACGCCGTCTCAACATGGTGCTGGTGTGCCGCATCTGGGTATCGACCCGTTCGCACTGGATTAT(Rhodopseudomonas TTTGCAGACCCGTACCCGGAACAGGAAACGCTGCGTGAAGCGGGTCCGGTGGTTTATCTGGATAAATGGAACGTTTACGGCGTCGCCCGCTATGCAGApalustris) AGTGTACGCGGTTCTGAATGATCCGCTGACCTTTTGCAGCTCTCGTGGCGTGGGTCTGTCAGACTTCAAAAAAGAAAAACCGTGGCGCCCGCCGTCGCTGATTCTGGAAGCTGATCCGCCGGCACATACGCGTACCCGTGCTGTCCTGTCAAAAGTGCTGTCGCCGGCGACCATGAAACGTCTGCGCGATGGTTTTGCGGCCGCAGCTGATGCCAAAATCGACGAACTGCTGGCACGTGGCGGTAACATTGATGCTATCGCGGACCTGGCCGAAGCATATCCGCTGTCAGTTTTTCCGGATGCCATGGGTCTGAAACAGGAAGGCCGCGAAAATCTGCTGCCGTACGCTGGTCTGGTCCTGAACGCATTCGGTCCGCCGAATGAACTGCGTCAGAGCGCCATTGAACGCTCTGCACCGCATCAGGCGTATGTTGCGGAACAGTGCCAACGTCCGAACCTGGCACCGGGCGGTTTTGGTGCATGTATTCACGCATTCTCCGATACGGGCGAAATCACCCCGGAAGAAGCTCCGCTGCTGGTGCGTAGTCTGCTGTCCGCCGGTCTGGACACCACGGTGAACGGTATCGCAGCAGCAGTTTACTGCCTGGCCCGCTTTCCGGATGAATTCGCTCGTCTGCGTGCGGACCCGAGCCTGGCCCGTAATGCATTTGAAGAAGCAGTTCGCTTCGAATCTCCGGTCCAGACGTTTTTCCGTACCACGACCCGCGATGTCGAACTGGCTGGTGCGACCATTGGCGAAGGTGAAAAAGTGCTGATGTTTCTGGGCAGCGCAAATCGTGACCCGCGTCGCTGGGATGACCCGGATCGTTATGACATCACGCGCAAAACCAGTGGTCATGTTGGCTTCGGTTCCGGCGTTCACATGTGTGTCGGTCAACTGGTGGCGCGTCTGGAAGGTGAAGTCGTGCTGGCTGCACTGGCACGTAAAGTGGCAGCAATTGAAATCGCAGGCCCGCTGAAACGCCGTTTTAACAATACCCTGCGTGGTCTGGAAAGCCTGCCGATTCAACTGACCCCGGCCTGA

extended to generate the full-length product amplified by flanking primers that included restriction enzyme sites for inserting the operon into the plasmid.

All construction plasmids described were verified by colony PCR or digestion and sequenced by Macrogen (Amsterdam, The Netherlands) or Genewiz (Cambridge, MA, USA).

\subsection{Growth conditions - p-coumaric and caffeic acid production}

E. coli cells for gene cloning, plasmid propagation, and inoculum preparation were grown in LB medium at $37^{\circ} \mathrm{C}$ and $200 \mathrm{rpm}$.

For $p$-coumaric acid and/or caffeic acid production, cultures were grown at $37^{\circ} \mathrm{C}$ in $50 \mathrm{~mL}$ LB to an optical density at $600 \mathrm{~nm}\left(\mathrm{OD}_{600}\right)$ of 0.4 . IPTG and/or aTc were added at the same time (unless otherwise specified) at a final concentration of $1 \mathrm{mM}$ and $100 \mathrm{ng} / \mathrm{mL}$, respectively, and the culture was incubated for $5 \mathrm{~h}$ at $26^{\circ} \mathrm{C}$. The cells were harvested by centrifugation, resuspended in $50 \mathrm{~mL}$ of modified M9 minimal salt medium containing (per liter): glucose (40 g), $\mathrm{Na}_{2} \mathrm{HPO}_{4}(6 \mathrm{~g}), \mathrm{KH}_{2} \mathrm{PO}_{4}(3 \mathrm{~g}), \mathrm{NH}_{4} \mathrm{Cl}$ $(1 \mathrm{~g}), \mathrm{NaCl}(0.5 \mathrm{~g}), \mathrm{CaCl}_{2}(17 \mathrm{mg}), \mathrm{MgSO}_{4}(58 \mathrm{mg})$, thiamine (340 mg) and $\mathrm{CaCO}_{3}(5 \mathrm{~g})$ (to control the $\mathrm{pH}$ ), and incubated at $26^{\circ} \mathrm{C}$ for $63 \mathrm{~h}$. Trace elements $\left[\mathrm{FeCl}_{3}(54 \mathrm{mg}\right.$ ), $\mathrm{ZnCl}_{2}$ (4 mg), $\mathrm{CoCl}_{2}$ (4 mg), $\mathrm{NaMoO}_{4}(4 \mathrm{mg}), \mathrm{CuCl}_{2}(2 \mathrm{mg})$ and $\left.\mathrm{H}_{2} \mathrm{BO}_{3}(1 \mathrm{mg})\right]$ and vitamins [riboflavin $(0.84 \mathrm{mg})$, folic acid $(0.084 \mathrm{mg})$, nicotinic acid $(12.2 \mathrm{mg})$, pyridoxine $(2.8 \mathrm{mg})$, biotin $(0.12 \mathrm{mg})$ and pantothenic acid $(10.8 \mathrm{mg})]$ were also supplemented to the M9 medium. Depending on the plasmid(s) present in the strain, $100 \mu \mathrm{g} / \mathrm{mL}$ of ampicillin, $100 \mu \mathrm{g} / \mathrm{mL}$ of spectinomycin and/or $50 \mu \mathrm{g} / \mathrm{mL}$ of kanamycin were added.
IPTG and/or aTc and substrates were added at time 0 of induction in M9 medium (unless otherwise stated): tyrosine, $3 \mathrm{mM}$ or $p$-coumaric acid, $2 \mathrm{mM}$. Samples of the supernatant $(1.5 \mathrm{~mL})$ were collected at time 0 and after 15, 24, 43 and $63 \mathrm{~h}$. All the experiments were done in triplicate and analyzed by high-performance liquid chromatography (HPLC).

\subsection{HPLC analysis of the products}

HPLC analysis was used to quantify $p$-coumaric acid and caffeic acid using a HPLC system from Jasco (Easton, MD, USA) (PU-2080 Plus Pump unit, LG-2080-02 Ternary Gradient unit, a DG-2080-53 3-Line Degasser unit, a UV-2075 Plus Intelligent UV/VIS Detector unit and AS-2057 Plus Intelligent Sampler unit) and a Grace Alltech Platinum EPS C18 column $(3 \mu \mathrm{m}, 150 \mathrm{~mm} \times 4.6 \mathrm{~mm}$ ) (Grace, Columbia, MD, USA). Mobile phases A and B were composed of water ( $0.1 \%$ trifluoroacetic acid) and acetonitrile, respectively. The following gradient was used at a flow rate of $1 \mathrm{~mL} / \mathrm{min}$ : $10-20 \%$ acetonitrile (mobile phase B) for $17 \mathrm{~min}$. Quantification was based on the peak areas of absorbance at $275 \mathrm{~nm}$ (tyrosine) and $310 \mathrm{~nm}$ ( $p$-coumaric acid and caffeic acid). The retention times of tyrosine, $p$-coumaric acid and caffeic acid were 3.3, 8.0 and $11.8 \mathrm{~min}$, respectively.

\subsection{Protein analysis}

E. coli K-12 MG1655(DE3) cells harboring pETDuet-1, pETDuet_TAL, pETDuet_C3H and pETDuet_TAL_C3H were grown in $\mathrm{LB}$ at $37^{\circ} \mathrm{C}$ to an $\mathrm{OD}_{600}$ of 0.6 . 
Table 4

Set of primers for PCR amplification (forward and reverse primers - FW and REV).

\begin{tabular}{|c|c|c|}
\hline Primer name & Primer sequence $^{a}$ & Restriction enzyme \\
\hline TAL_pET_pCDF_pRSF_FW & GGCGCGCCAAATGGCTCCGCGTCCG & AscI \\
\hline TAL_pET_pCDF_pRSF_REV & GCGGCCGCTTATGCCAGCATTTTCAGCAG & Not $\mathrm{I}$ \\
\hline TAL_pKVS45_FW & 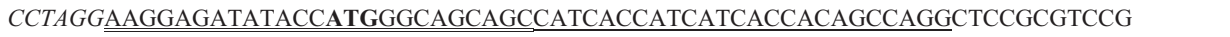 & AvrII \\
\hline TAL_pKVS45_REV & GGATCCTTATGCCAGCATTTTC & BamHI \\
\hline C3H_pET_FW & AGATCTCATGACGATTACCTCTCCGGC & BglII \\
\hline C3H_pET_REV & CTCGAGCGTGCCCGGGTTAATCAG & XhoI \\
\hline C3H_pKVS45_FW & CCTAGGAAGGAGATATACCATGGGCAGCAGCCATCACCATCATCACCACAGCCAGACGATTACCTCTCCGGCA & AvrII \\
\hline C3H_pKVS45_REV & GGATCCTTACGTGCCCGGGTTAATCAG & BamHI \\
\hline C3H_pCDF_pRSF_FW & GGCGCGCCAAATGACGATTACCTCTCCGG & $A s c \mathrm{I}$ \\
\hline C3H_pCDF_pRSF_REV & AAGCTTTTACGTGCCCGGGTTAATC & HindIII \\
\hline CYP(+7aa)_pCDF_FW & CATATG $\underline{\text { CATCACCATCATCACCACATGACGACCGCTCCGAGCCT }}$ & NdeI \\
\hline CYP_pCDF_FW & CATATGCATCACCATCATCACCACATGCCGGTTACGACG & NdeI \\
\hline CYP_pCDF_REV & CTCGAGTCAGGCCGGGGTC & XhoI \\
\hline TAL_op_FW & GGATCCAATGGCTCCGCGTC & BamHI \\
\hline TAL_op_REV & CGTCATGGTATATCTCCTTTTATGCCAGCATTTTCAGC & - \\
\hline CYP(+7aa)_op_FW & ATAAAAGGAGATATACCATGACGACCGCTC & - \\
\hline CYP_op_REV & AAGCTTTCAGGCCGGGGTC & HindIII \\
\hline TAL_op2_REV & GGCATGGTATATCTCCTTTTATGCCAGCATTTTCAGC & - \\
\hline CYP_op2_FW & ATAAAAGGAGATATACCATGCCGGTTACGACG & - \\
\hline Pdr_pKVS45_FW & 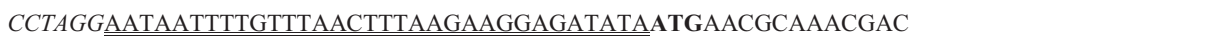 & NdeI \\
\hline Pdr_pKVS45_REV & GAGCTCTCAGGCACTACTCAGTTCAGC & SacI \\
\hline Pux_pKVS45_FW & GGATCCAATAATTTTGTTTAACTTTAAGAAGGAGATATAATGCCCAGTATCACGTTCATTCTT & BamHI \\
\hline Pux_pKVS45_REV & GCATGCTCAGACCTGACGATCCGGAAT & $S p h \mathrm{I}$ \\
\hline Pdr_Pux_op_pET_FW & GAATTCAATGAACGCAAACGACAAC & EcoRI \\
\hline Pdr_Pux_op_pET_REV & GATATCTCAGACCTGACGATCCG & EcoRV \\
\hline
\end{tabular}

a Start and stop codons in bold, occasionally the start codon is placed upstream of the His $_{6}$-tag sequence and no stop codon is included because of the presence of a Strep-tag; restriction sites in italic; $\mathrm{His}_{6}$-tag underlined; the Ribosome Binding Site (RBS) and spacer are double underlined. In order for the sequence to remain in frame one or two bases were occasionally added between the restriction site and the gene start codon.

IPTG was added at a final concentration of $1 \mathrm{mM}$, and the culture was incubated for $24 \mathrm{~h}$. Samples ( $10 \mathrm{~mL}$ culture medium) were taken at times 0, 5 and $24 \mathrm{~h}$. Samples were centrifuged and the cells were resuspended in phosphate-buffered saline (PBS: $137 \mathrm{mM} \mathrm{NaCl}, 2.7 \mathrm{mM} \mathrm{KCl}, 10 \mathrm{mM} \mathrm{Na}_{2} \mathrm{PO}_{4}, 1.8 \mathrm{mM} \mathrm{KH}_{2} \mathrm{PO}_{4}$, pH 7.4) and further disrupted by sonication on ice for $3 \mathrm{~min}$. After centrifugation the protein concentration from the resulting supernatant was determined using Protein Assay Dye Reagent Concentrate (BioRad, Hercules, CA, USA) with bovine serum albumin (BSA) (NEB) as a standard. The expression levels of TAL and $\mathrm{C} 3 \mathrm{H}$ were evaluated through sodium dodecyl sulfate polyacrylamide gel electrophoretic (SDS-PAGE). Fifteen to $20 \mu \mathrm{g}$ of total protein were loaded onto a 4-20\% Mini-PROTEAN ${ }^{\circledR}$ TGX $^{\mathrm{TM}}$ Precast Gels (BioRad). The protein marker used was Precision Plus Protein ${ }^{\mathrm{TM}}$ Unstained (BioRad). For gel staining, Bio-Safe Coomassie Stain (BioRad) was used.

\section{Results and discussion}

\subsection{Selection of the appropriate enzyme sources}

TAL was chosen from the red yeast $R$. glutinis, since it was reported to have the highest TAL activity and a low PAL/TAL catalytic activity ratio [22-24]. TAL prefers tyrosine and is therefore favored over PAL and $\mathrm{C} 4 \mathrm{H}$, both of which are required to begin the pathway from phenylalanine (Fig. 1). This decreases the pathway number of steps and at the same time eliminates the issues associated with the use of $\mathrm{C} 4 \mathrm{H}$. C4H is a $\mathrm{P} 450$-dependent monooxygenase and the functional expression of plant P450 enzymes is always hard to achieve in bacteria, which is mainly due to the absence of cytochrome $\mathrm{P} 450$ reductases (CPRs)/redox partners in E. coli needed for electron transfer, and to the absence of endoplasmatic reticulum which prevents the efficient translational of the membrane signal modules of microsomal P450 enzymes [25]. C3H from S. espanaensis was chosen as it is one of the rare cytochrome P450 enzymes that was successfully expressed in E. coli [15] (Table 1). CYP199A2 from $R$. palustris was chosen as it was effectively used in previous studies to achieve one of the highest caffeic acid production from p-coumaric acid [8].

\subsection{Production of p-coumaric acid from tyrosine using TAL}

In order to study $p$-coumaric acid production from tyrosine, codon-optimized TAL was cloned in pETDuet-1, pCDFDuet-1, pRSFDuet- 1 and pKVS45. Fig. 2 illustrates $p$-coumaric acid production from $3 \mathrm{mM}$ of tyrosine. $p$-Coumaric acid was also produced from endogenous tyrosine in the presence of PCDFDuet_TAL, but in a very low quantity compared to conditions with tyrosine

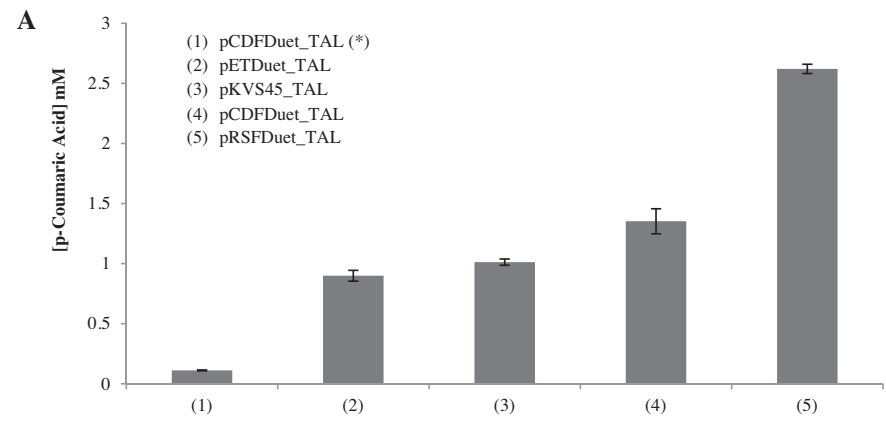

B

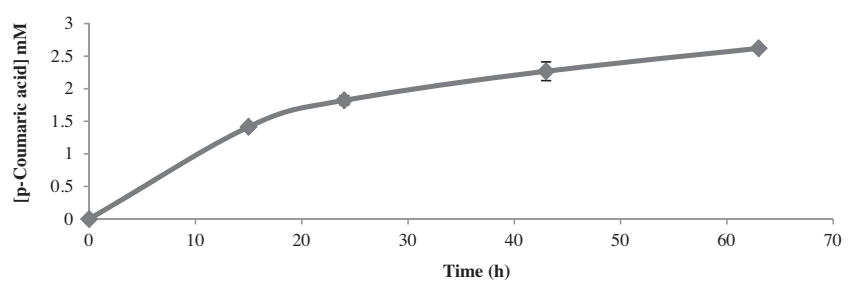

Fig. 2. Production of $p$-coumaric acid using TAL from Rhodotorula glutinis using different plasmids after $63 \mathrm{~h}(\mathrm{~A})$ and using pRSFDuet_TAL during $63 \mathrm{~h}$ in M9 medium (B). $\left({ }^{*}\right)$ no substrate added. TAL: tyrosine ammonia lyase. 


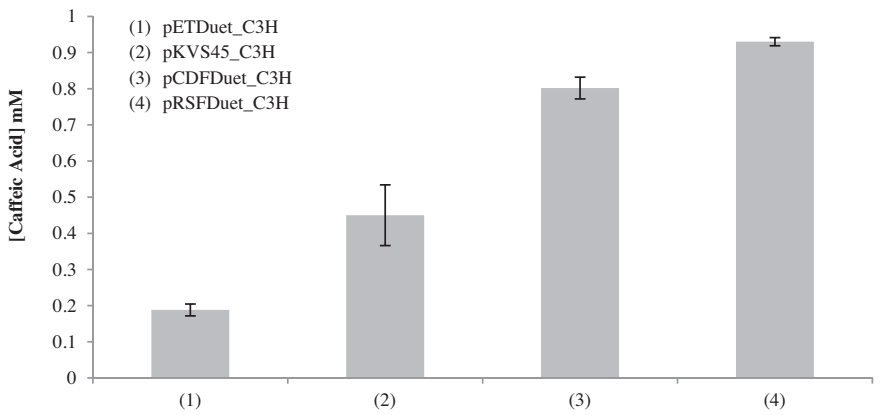

Fig. 3. Production of caffeic acid using opC $3 \mathrm{H}$ from Saccharothrix espanaensis. $\mathrm{C} 3 \mathrm{H}$ : 4-coumarate 3-hydroxylase.

supplemented. Since the endogenous tyrosine is not enough to produce $p$-coumaric acid in high concentrations, two strategies can be used, namely supplement the medium with tyrosine or engineer $E$. coli to overproduce tyrosine from glucose. $p$-Coumaric acid production using TAL was found to be highly dependent on the plasmid chosen. The highest production obtained was $2.62 \mathrm{mM}$ ( $472 \mathrm{mg} / \mathrm{L}$ ) and it was achieved with pRSFDuet-1, which is a high copy number plasmid. In this case, the product yield was 0.87 (mol $p$-coumaric acid/mol tyrosine) and the remaining tyrosine was presumably used for growth and primary metabolism since no tyrosine was detected by HPLC. Santos et al. [26] used a codon-optimized $R$. glutinis TAL with a $80 \%$ similarity to the one used in this study. Although both plasmids (pETDuet-1 and pTrcHis2B) have a pBR322 origin, they have different promoters, with the T7 system being stronger than the trc promoter. The $p$-coumaric acid production obtained using pETDuet_TAL (the lowest production in the current study) was higher than that reported by Santos et al. [26] after $72 \mathrm{~h}$ using pTrcHis2B $(104 \mathrm{mg} / \mathrm{L}-0.61 \mathrm{mM})$. They obtained a product yield of 0.23 (mol $p$-coumaric acid/mol tyrosine) in a E. coli $\mathrm{K} 12$ MG1655(DE3) strain. From analyzing these results it can be concluded that the R. glutinis TAL used in our study and the expression systems chosen are a very good option to produce $p$-coumaric acid.

Fig. 2B shows the production of $p$-coumaric acid in the strain harboring pRSFDuet_TAL over time $(63 \mathrm{~h})$. The results showed that the $p$-coumaric concentration increases along time, and this trend was also observed when using other plasmid constructions (data not shown). Although $63 \mathrm{~h}$ of incubation is a long time, it is not unusual to prolong the fermentations more than $24 \mathrm{~h}$ in the caffeic acid production to obtain higher titers and yields, as can be observed in Table 1. Albeit the incubations can be performed at higher temperatures, the production would be lower since our preliminary results showed that using TAL and the other enzymes used in this study at $30^{\circ} \mathrm{C}$ and $37^{\circ} \mathrm{C}$ leads to lower titers than $26^{\circ} \mathrm{C}$ (data not shown).

\subsection{Production of caffeic acid from p-coumaric acid using $\mathrm{C} 3 \mathrm{H}$}

Caffeic acid was produced from $p$-coumaric acid using $S$. espanaensis $\mathrm{C} 3 \mathrm{H}$ (Fig. 3). $\mathrm{C} 3 \mathrm{H}$, although being a plant cytochrome P450 enzyme, has been successfully expressed in E. coli $[15,17,18]$. As previously shown in the $p$-coumaric acid production from tyrosine (Fig. 2), the highest caffeic acid titer was also obtained with the high copy number plasmid pRSFDuet-1. The titer obtained was around $0.93 \mathrm{mM}(168 \mathrm{mg} / \mathrm{L})$, corresponding to a product yield of 0.47 ( $\mathrm{mol}$ caffeic acid/mol $p$-coumaric acid).

\subsection{Production of caffeic acid from tyrosine using TAL and $\mathrm{C} 3 \mathrm{H}$}

In a second phase of the current study, TAL and $\mathrm{C} 3 \mathrm{H}$ were combined to produce caffeic acid from $3 \mathrm{mM}$ of tyrosine (Fig. 4). In

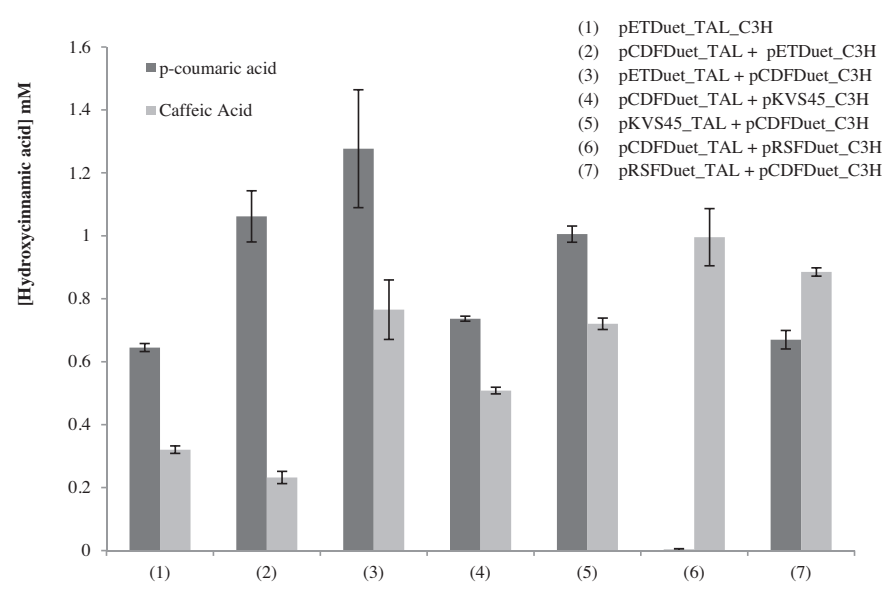

Fig. 4. Production of caffeic acid using opTAL from Rhodotorula glutinis and opC $3 \mathrm{H}$ from Saccharothrix espanaensis. TAL: tyrosine ammonia lyase; $\mathrm{C} 3 \mathrm{H}$ : 4-coumarate 3-hydroxylase.

a first approach, the genes were cloned together in pETDuet-1. When these genes were combined, the production of caffeic acid increased $170 \%$. This increase is probably due to the fact that in this case the $p$-coumaric concentration in the medium is lower than when it is added directly, thus reducing the toxic effect to the cells as previously described in the literature [9,10,27-30]. To confirm that the addition of $p$-coumaric acid had a toxic effect to the cells, $p$-coumaric acid and tyrosine were added separately to E. coli harboring pETDuet-1 and pETDuet_TAL_C3H. When $p$-coumaric acid was added, the $E$. coli cultures had a lower growth rate and the $\mathrm{OD}_{600}$ was $10-11 \%$ lower than when tyrosine was added (data not shown). Moreover, the protein expression was found to be lower. When only TAL is cloned in the pETDuet- 1 plasmid the protein band in the SDS gel could be clearly visualized ( $76.34 \mathrm{kDa}$ ) (data not shown). However, when TAL was combined with $\mathrm{C} 3 \mathrm{H}$, protein production was not observed maybe due to the metabolic burden imposed on the host cells by the expression of the two proteins in the same plasmid. Although in small amounts, a band around $56.33 \mathrm{kDa}$ corresponding to $\mathrm{C} 3 \mathrm{H}$ production could be observed.

Cloning TAL in pCDFDuet- 1 and $\mathrm{C} 3 \mathrm{H}$ in pETDuet- 1 led to results very similar to the experiments in which these enzymes were used alone to produce $p$-coumaric acid or caffeic acid, respectively (Fig. 2A and Fig. 3). This occurs because the expression of TAL when alone in the plasmid is very high, leading to high production of $p$-coumaric acid. Consequently, caffeic acid amounts are comparable to the ones obtained when $p$-coumaric acid is added as substrate. Similar results were observed with the combination pETDuet_TAL and pCDFDuet_C3H. The production of $p$-coumaric acid was $1.28 \mathrm{mM}$ and caffeic acid was $0.77 \mathrm{mM}$. Since caffeic acid is produced from $p$-coumaric, this suggests that in total more than $2 \mathrm{mM}$ of $p$-coumaric acid was produced. When only pETDuet_TAL was used (Fig. 2A), the maximum $p$-coumaric acid production obtained was $0.9 \mathrm{mM}$, which demonstrates that tyrosine can be converted faster if $p$-coumaric acid is being converted to the next product. Again we observed that caffeic acid production does not increase (compared to the cases when only $\mathrm{C} 3 \mathrm{H}$ is used and the substrate is $p$-coumaric acid) since the $p$-coumaric acid concentration in the medium is still very high. The combinations pKVS45_TAL/pCDFDuet_C3H, pCDFDuet_TAL/pKVS45_C3H and pRSFDuet_TAL/pCDFDuet_C3H showed very similar results.

The combination pCDFDuet_TAL/pRSFDuet_C3H is very interesting as almost all the $p$-coumaric acid produced is converted to caffeic acid. In the end, only around $3 \mu \mathrm{M}$ of $p$-coumaric acid is detected by HPLC and the concentration in time was never higher than $0.15 \mathrm{mM}$, meaning that almost all the $p$-coumaric acid being 


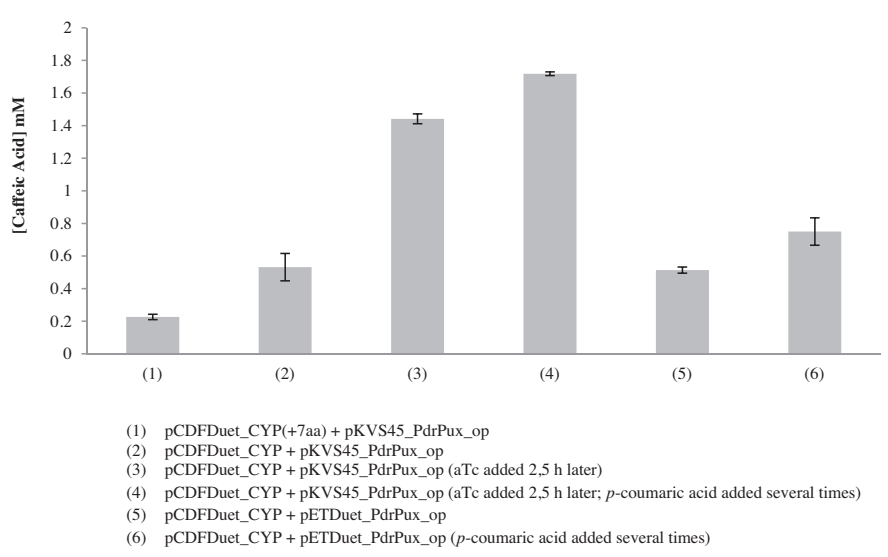

Fig. 5. Production of caffeic acid from p-coumaric acid using CYP199A2 from Rhodotorula palustris. CYP: cytochrome P450 CYP199A2.

produced was being converted by $\mathrm{C} 3 \mathrm{H}$ to caffeic acid. A final caffeic acid concentration of around $1 \mathrm{mM}(180 \mathrm{mg} / \mathrm{L})$ was obtained. This combination enabled the highest yield from tyrosine with an additional benefit of having in the end a very low amount of the intermediate $p$-coumaric acid, contrary to what was observed in the other cases.

Zhang and Stephanopoulos [18] used codon optimized TAL from R. glutinis and $\mathrm{C} 3 \mathrm{H}$ from S. espanaensis to produce caffeic acid. Also, the authors used a tyrosine over producing strain and no tyrosine limitation was observed during the caffeic acid production. After several medium optimizations, the highest titer they reported after $72 \mathrm{~h}$ was $106 \mathrm{mg} / \mathrm{L}$ (Table 1 ), which is 1.7 times lower than the maximum titer obtained in the current study after $63 \mathrm{~h}$. Although those authors used the same plasmid to carry C3H (pRSFDuet-1), they used the pTrcHis2B plasmid to carry TAL, which was previously described by Santos et al. [26] and that we concluded it is not the best plasmid for this gene and to produce $p$-coumaric acid (see Section 3.2). Our study reports the highest titer of caffeic acid produced so far using the combination of TAL and $\mathrm{C} 3 \mathrm{H}$ genes.

\subsection{Production of caffeic acid from p-coumaric acid using CYP199A2}

Until the recent studies published using 4HPA3H $[9,10]$, CYP199A2 gene from $R$. palustris was reported to produce the highest amounts of caffeic acid from $p$-coumaric acid [8]. The results obtained in our study with CYP199A2 are summarized in Fig. 5. CYP199A2 was cloned in pCDFDuet-1 and its redox partners, Pdr and Pux, were expressed in another plasmid (pKVS45 or pETDuet1 ) as part of an operon as described before $[31,32]$. The first results obtained with CYP199A2 in the caffeic acid production were surprisingly low as compared to the Furuya et al. [8] report. After analyzing the CYP199A2 DNA sequence it was verified that those authors did not use the first $21 \mathrm{bp}$ of CYP199A2 to clone the gene. This decision was based on software results that annotated the 8th CYP199A2 amino acid (GTG) as a start codon before the sequence was published (T. Furuya, personal communication). We also confirmed that, for example, EasyGene 1.2b Server [33,34] identified the 8th amino acid as the start codon. Based on this, we cloned CYP199A2 without the first 7 amino acids. The production using this new CYP199A2 increased considerably the caffeic acid production compared to the original clone (CYP199A2(+7aa)). Additionally, it was found that the production was more than 2.7 times higher when the inducer of pKVS45_Pdr_Pux_op, aTc, was added $2.5 \mathrm{~h}$ after addition of IPTG (to induce CYP199A2 expression). The delay of induction can alleviate the metabolic burden of several plasmids $[26,35]$. Since pKVS45 has CYP199A2 redox partners (Pdr and Pux)

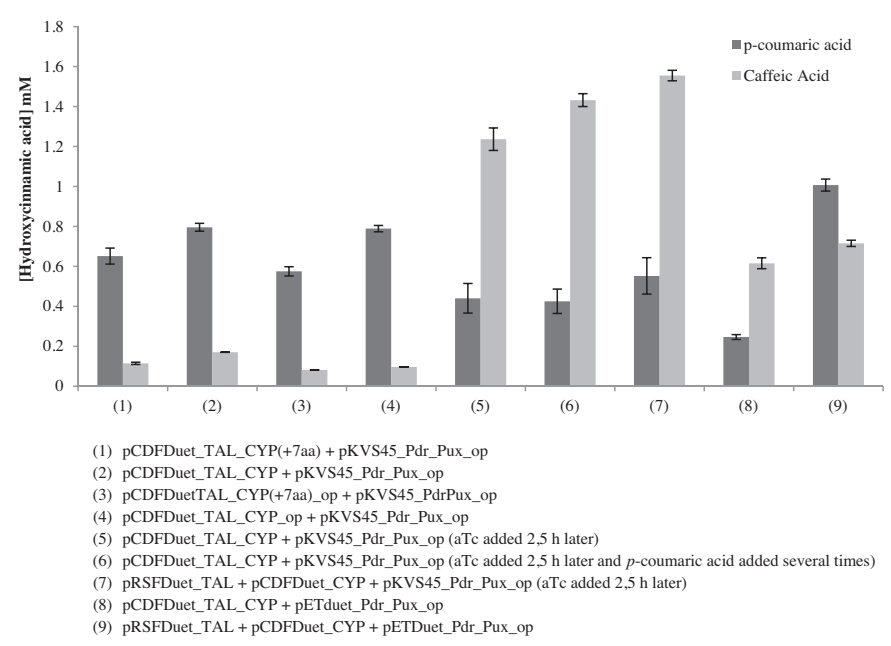

Fig. 6. Production of caffeic acid using TAL from Rhodotorula glutinis and CYP199A2 from Rhodopseudomonas palustris. TAL: tyrosine ammonia lyase; CYP: cytochrome P450 CYP199A2.

and these proteins are only needed after CYP199A2 is present in a significant concentration to support its catalytic activity (NADPHand $\mathrm{O}_{2}$-dependent hydroxylation reactions), their expression can be delayed. The results obtained with CYP199A2 in this case were 1.8 times better than the one obtained with $\mathrm{C} 3 \mathrm{H}$ in pCDFDuet-1 adding $p$-coumaric acid (Fig. 3 ). Nevertheless, to improve the yield and taking into consideration that the addition of a high concentration of $p$-coumaric acid can have a detrimental effect on the caffeic acid production, as discussed before, a different feeding system was tested: $1 \mathrm{mM}$ of $p$-coumaric acid was added at time 0 of induction in M9 medium and $0.5 \mathrm{mM}$ added at $5 \mathrm{~h}$ and $24 \mathrm{~h}$. Caffeic acid production increased to $1.72 \mathrm{mM}(310 \mathrm{mg} / \mathrm{L})$ using this three step feeding. This approach was successfully demonstrated before for the production of caffeic acid $[9,10]$ and allowed us to obtain a product yield of 0.86 (mol caffeic acid/mol $p$-coumaric acid) after $63 \mathrm{~h}$. Furuya et al. [8] obtained a maximum yield of 0.75 (mol caffeic acid/mol p-coumaric acid) after $24 \mathrm{~h}$ using glycerol as energy source. When the authors used glucose, the maximum yield obtained after $24 \mathrm{~h}$ was around 0.46 (mol caffeic acid/mol $p$-coumaric acid), thus very similar to the one obtained in the current study after $24 \mathrm{~h}-0.47$ ( $\mathrm{mol}$ caffeic acid/mol $p$-coumaric acid), which suggests that glycerol is a more effective energy source to regenerate $\mathrm{NADH}$ from $\mathrm{NAD}^{+}[8]$.

Since pKVS45 time of induction with aTc seems to limit caffeic acid production, pETDuet-1, that is induced using IPTG similarly to pCDFDuet-1, was chosen to clone the CYP199A2 redox partners and evaluate if the caffeic acid production could be increased. However, the results obtained with pETDuet- 1 were very similar to the ones obtained with pKVS45 induced at time 0 . This result is not surprising since pKVS45 alone, or combined with pCDFDuet-1, gave better overall results using TAL and $\mathrm{C} 3 \mathrm{H}$ than the pETDuet-1 plasmid (Figs. 2-4).

\subsection{Production of caffeic acid from tyrosine using TAL and CYP199A2}

To produce caffeic acid from tyrosine, TAL and CYP199A2 were combined using different approaches, namely together in the same plasmid but in different MCSs (TAL in MCS1 and CYP199A2 in MCS2), or in an operon in MCS1 (Fig. 6). Both CYP199A2 sequences were tested and again it was concluded that CYP199A2 starting at the 8 th amino acid provides better results. The low caffeic acid concentration obtained was due to the addition of aTc at time zero of induction. However, even with a low concentration, it is possible 
to conclude that the genes work better when cloned in different MCSs than when cloned in an operon. Thus, this approach was chosen to proceed with other tests including pKVS45 later induction with aTc; three phases of $p$-coumaric acid addition; and the use of another plasmid to carry CYP199A2 redox partners (pETDuet-1). The results obtained were very similar to the ones found with only CYP199A2 in the plasmid (Fig. 5). The expression of TAL in a different plasmid (pRSFDuet-1) improved caffeic acid production. The highest caffeic acid production was $1.56 \mathrm{mM}(280 \mathrm{mg} / \mathrm{L})$. According to these results, CYP199A2 with its redox partners seems to be a better option than $\mathrm{C} 3 \mathrm{H}$ to produce caffeic acid from tyrosine or p-coumaric acid.

Based on the above discussion, we believe that it would be advisable to, in the future, clone CYP199A2 with its redox partners in different plasmids and combine them with TAL to confirm if caffeic acid production can be improved without a high accumulation of the intermediate as its accumulation may result in suboptimal production titers. Although no kinetic parameters were determined in our study, it was possible to observe that over time the conversion of tyrosine to $p$-coumaric acid was faster than the conversion of $p$-coumaric acid to caffeic acid. The faster conversion of tyrosine to $p$-coumaric acid leads to the accumulation of $p$-coumaric acid which represents a drawback to the caffeic acid production since its toxicity leads to an even more pronounced decrease of the production. The kinetic parameters of the enzymes used in this study should be determined, especially regarding the $\mathrm{C} 3 \mathrm{H}$, since TAL and CYP199A2 kinetic parameters were characterized by Xue et al. [22] and Furuya et al. [8], respectively. Furthermore, it will be important to evaluate a combination of plasmids that allows a fine-tuned production like the one observed when TAL was cloned in pCDFDuet-1 and $\mathrm{C} 3 \mathrm{H}$ in pRSFDuet-1, where no $p$-coumaric acid was accumulated (Fig. 4). Also, to improve the yield and to avoid the need of two separate stages of cultivation for biomass/protein generation and caffeic acid production, the use of potassium phosphate buffer $[8,9]$ or MOPS $[18,26]$ with glucose or glycerol should be tested. The use of M9 minimal medium without the production of biomass and protein in LB does not allow obtaining productions as high as the ones obtained by first using LB and then transferring the cells to M9 (data not shown).

Caffeic acid has for a long time been recognized for its therapeutic properties, which makes it an attractive target for metabolic engineering and synthetic biology. We have successfully designed a pathway for the production of caffeic acid via metabolic engineering approaches in E. coli. We tested different genetic arrangements with two (or four) genes to balance the expression of the enzymes and achieve an optimized performance, and we obtained significantly different levels of caffeic acid productions. The layout of genes and operons in the plasmid, as well as the use of different plasmids had an enormous impact on gene expression. In addition, codon-optimization when expressing heterologous genes in $E$. coli was considered to improve gene expression. The repeated addition of the substrate and the delay in the induction of protein expression also led to an increase of the titers by decreasing the toxicity of $p$-coumaric acid and the metabolic burden of heterologous protein expression.

In conclusion, the caffeic acid is a phenylpropanoic acid and this pathway can be further used to produce other products of the phenylpropanoid pathway from tyrosine like flavonoids, stilbenoids, isoflavonoids and curcuminoids. Until now the biosynthesis of these compounds is in the range of the titers obtained in this study for $p$-coumaric acid and caffeic acid or much lower. Therefore, the strategy of adding $p$-coumaric acid at concentrations as high as $20 \mathrm{mM}$, concentrations used in some studies for the caffeic acid production (Table 1), was considered unreasonable, especially knowing that high concentrations of $p$-coumaric acid are toxic to the cells. For the production system to be even more economically viable, the use of a tyrosine overproducing strain should be considered.

\section{Competing interests}

The authors declare no competing interests.

\section{Acknowledgments}

This work was supported by FEDER funds through the COMPETE and ON2 program and through National funds of FCT in the scope of the project FCOMP-01-0124-FEDER-027462, PEst-OE/EQB/LA0023/2013, NORTE-07-0124-FEDER-000028 and NORTE-07-0124-FEDER-000027. Financial support for this work was provided by FCT grant SFRH/BD/51187/2010 and SYNBIOBACTHER project (PTDC/EBB-BIO/102863/2008).

\section{References}

[1] Mori H, Iwahashi H. Antioxidant activity of caffeic acid through a novel mechanism under UVA irradiation. J Clin Biochem Nutr 2009;45:49-55.

[2] Chao P, Hsu C, Yin M. Anti-inflammatory and anti-coagulatory activities of caffeic acid and ellagic acid in cardiac tissue of diabetic mice. Nutr Metab 2009;6:1-8.

[3] Prasad NR, Karthikeyan A, Karthikeyan S, Reddy BV. Inhibitory effect of caffeic acid on cancer cell proliferation by oxidative mechanism in human HT-1080 fibrosarcoma cell line. Mol Cell Biochem 2011;349:11-9.

[4] Ikeda K, Tsujimoto K, Uozaki M, Nishide M, Suzuki Y, Koyama AH, et al. Inhibition of multiplication of herpes simplex virus by caffeic acid. Int J Mol Med 2011;28:595-8.

[5] Jung UJ, Lee M-K, Park YB, Jeon S-M, Choi M-S. Antihyperglycemic and antioxidant properties of caffeic acid in $\mathrm{db} / \mathrm{db}$ mice. J Pharmacol Exp Ther 2006;318:476-83.

[6] Takeda H, Tsuji M, Inazu M, Egashira T, Matsumiya T. Rosmarinic acid and caffeic acid produce antidepressive-like effect in the forced swimming test in mice. Eur J Pharmacol 2002;449:261-7.

[7] Xing Y, Peng H.-y., Zhang M.-X., Li X, Zeng W.-W., Yang X-e. Caffeic acid product from the highly copper-tolerant plant Elsholtzia splendens postphytoremediation: its extraction, purification, and identification. J Zhejiang Univ Sci B 2012:13:487-93.

[8] Furuya T, Arai Y, Kino K. Biotechnological production of caffeic acid by bacterial cytochrome P450 CYP199A2. Appl Environ Microbiol 2012;78:6087-94.

[9] Furuya T, Kino K. Catalytic activity of the two-component flavin-dependent monooxygenase from Pseudomonas aeruginosa toward cinnamic acid derivatives. Appl Microbiol Biotechnol 2013;98:1145-54.

[10] Huang Q, Lin Y, Yan Y. Caffeic acid production enhancement by engineering a phenylalanine over-producing Escherichia coli strain. Biotechnol Bioeng 2013;110:3188-96.

[11] Miyahisa I, Kaneko M, Funa N, Kawasaki H, Kojima H, Ohnishi Y, et al. Efficient production of (2S)-flavanones by Escherichia coli containing an artificial biosynthetic gene cluster. Appl Microbiol Biotechnol 2005;68:498-504.

[12] Hwang EI, Kaneko M, Ohnishi Y, Horinouchi S. Production of plant-specific flavanones by Escherichia coli containing an artificial gene cluster. Appl Environ Microbiol 2003;69:2699-706.

[13] Watts KT, Lee PC, Schmidt-Dannert C. Exploring recombinant flavonoid biosynthesis in metabolically engineered Escherichia coli. ChemBioChem 2004;5:500-7

[14] Berner M, Krug D, Bihlmaier C, Vente A, Müller R, Bechthold A. Genes and enzymes involved in caffeic acid biosynthesis in the actinomycete Saccharothrix espanaensis. J Bacteriol 2006;188:2666-73.

[15] Choi O, Wu C-Z, Kang SY, Ahn JS, Uhm T-B, Hong Y-S. Biosynthesis of plantspecific phenylpropanoids by construction of an artificial biosynthetic pathway in Escherichia coli. J Ind Microb Biotechnol 2011;38:1657-65.

[16] Lin Y, Yan Y. Biosynthesis of caffeic acid in Escherichia coli using its endogenous hydroxylase complex. Microb Cell Fact 2012;11:1-9.

[17] Kang S-Y, Choi O, Lee JK, Hwang BY, Uhm T-B, Hong Y-S. Artificial biosynthesis of phenylpropanoic acids in a tyrosine overproducing Escherichia coli strain. Microbial Cell Fact 2012;11:1-9.

[18] Zhang H, Stephanopoulos G. Engineering E. coli for caffeic acid biosynthesis from renewable sugars. Appl Microbiol Biotechnol 2013;97:3333-41.

[19] Nielsen DR, Yoon SH, Yuan CJ, Prather KL. Metabolic engineering of acetoin and meso-2,3-butanediol biosynthesis in E. coli. Biotechnol J 2010:5:274-84

[20] Solomon KV, Sanders TM, Prather KL. A dynamic metabolite valve for the control of central carbon metabolism. Metab Eng 2012;14:661-71.

[21] Horton RM, Hunt HD, Ho SN, Pullen JK, Pease LR. Engineering hybrid genes without the use of restriction enzymes: gene splicing by overlap extension. Gene 1989;77:61-8.

[22] Xue Z, McCluskey M, Cantera K, Ben-Bassat A, Sariaslani FS, Huang L. Improved production of $p$-hydroxycinnamic acid from tyrosine using a novel thermostable phenylalanine/tyrosine ammonia lyase enzyme. Enzyme Microb Technol 2007;42:58-64. 
[23] Gatenby AA, Sariaslani S, Tang X-S, Qi WW, Vannelli T. Bioproduction of parahydroxycinnamic acid. US Patent $6,368,837 ; 2002$

[24] Vannelli T, Wei Qi W, Sweigard J, Gatenby AA, Sariaslani FS. Production of $p$-hydroxycinnamic acid from glucose in Saccharomyces cerevisiae and Escherichia coli by expression of heterologous genes from plants and fungi. Metab Eng 2007;9:142-51.

[25] Chapple C. Molecular-genetic analysis of plant cytochrome P450-dependent monooxygenases. Annu Rev Plant Biol 1998;49:311-43.

[26] Santos CNS, Koffas M, Stephanopoulos G. Optimization of a heterologous pathway for the production of flavonoids from glucose. Metab Eng 2011:13:392-400.

[27] Barthelmebs L, Diviès C, Cavin J-F. Expression in Escherichia coli of native and chimeric phenolic acid decarboxylases with modified enzymatic activities and method for screening recombinant $E$. coli strains expressing these enzymes. Appl Environ Microbiol 2001;67:1063-9.

[28] Jung D-H, Choi W, Choi K-Y, Jung E, Yun H, Kazlauskas RJ, et al. Bioconversion of p-coumaric acid to p-hydroxystyrene using phenolic acid decarboxylase from B. amyloliquefaciens in biphasic reaction system. Appl Microbiol Biotechnol 2013;97:1501-11.
[29] Shin S-Y, Han NS, Park Y-C, Kim M-D, Seo J-H. Production of resveratrol from $p$-coumaric acid in recombinant Saccharomyces cerevisiae expressing 4 coumarate: coenzyme A ligase and stilbene synthase genes. Enzyme Microb Technol 2011:48:48-53.

[30] Watts KT, Lee PC, Schmidt-Dannert C. Biosynthesis of plant-specific stilbene polyketides in metabolically engineered Escherichia coli. BMC Biotechnol 2006;6:1-12.

[31] Furuya T, Kino K. Discovery of 2-naphthoic acid monooxygenases by genome mining and their use as biocatalysts. ChemSusChem 2009;2:645-9.

[32] Furuya T, Kino K. Regioselective oxidation of indole- and quinolinecarboxylic acids by cytochrome P450 CYP199A2. Appl Microbiol Biotechnol 2010;85:1861-8.

[33] Larsen TS, Krogh A. EasyGene - a prokaryotic gene finder that ranks ORFs by statistical significance. BMC Bioinform 2003;4:1-15.

[34] Nielsen P, Krogh A. Large-scale prokaryotic gene prediction and comparison to genome annotation. Bioinformatics 2005;21:4322-9.

[35] Wu J, Du G, Zhou J, Chen J. Metabolic engineering of Escherichia coli for (2S)pinocembrin production from glucose by a modular metabolic strategy. Metab Eng 2013;16:48-55. 